УДК 621.9.048

DOI 10.36910/6775-2313-5352-2021-18-6

Денисюк В.Ю., Симонюк В.П., Лапченко Ю.С., Кайдик О.Л., Пташенчук В.В.

Луцький національний технічний університет

\title{
ДОСЛІДЖЕННЯ ПРОЦЕСІВ ОБРОБКИ ДЕТАЛЕЙ ПРИ УДАРНО-ІМПУЛЬСНОМУ НАВАНТАЖЕННІ ВІБРОБУНКЕРА
}

В статті представлені результати досліджень закономірностей цчиркулячійного вихрового руху робочого середовища та переміщення корпусу вібробункера при його симетричному ударно-імпульсному навантаженні. Встановлено, щуо ударно-імпульсні навантаження на вібробункер призводять до виникнення повільного ичиркулячійного руху робочого середовища, який інтенсифікується при несиметричному ударному навантаженні. Представлено результати експериментальних досліджень процесу вібраційної обробки деталей, перевірено відтворюваність експерименту та достовірність отриманих результатів. Здійснено аналіз технологічних можливостей віброобробки в широкому діапазоні частоти та розмаху коливань. Наочно представлено причини проблематичності вибору оптимальних режимів віброобробки та можливі напрямки їх подолання. Здійснено моделювання різних режимів роботи вібраційної установки. Аналіз результатів дав можливість виявити принципи оптимального підбору режимів віброобробки. Встановлено спосіб досягнення режиму роботи вібраційної установки з максимально ефективним використанням механічної енергії коливань.

Ключові слова: вібраційна абразивна обробка, вібробункер, цииркуляційний рух, електромагніт, абразивний матеріал, ударна хвиля.

Постановка проблеми. Актуальність вібраційних методів обробки деталей пояснюється перевагами цього методу над традиційними фінішними операціями. Віброобробка дозволяє забезпечити механізацію процесу обробки, покращити обробку геометрично-складних зовнішніх і внутрішніх важкодоступних поверхонь деталей, а також обробку крихких i нежорстких деталей без порушення їх геометричної форми та пошкодження поверхонь [1]. Застосування віброобробки в якості фінішної операції дозволяє суттєво знизити собівартість виготовлення деталей і забезпечує отримання мікронерівностей порядку $0,15 \div 0,25$ мкм. У ряді випадків вона може замінити доводку, собівартість якої в $4-5$ разів вища.

Процес вібраційної обробки полягає в послідовному нанесенні по поверхні оброблюваних деталей великої кількості мікроударів, а також нанесенні великої кількості мікроподряпин на поверхні частинками робочого середовища. Основою процесу є механічне або механо-хімічне знімання дрібних частинок металу та його окислів з оброблюваної поверхні, а також вигладжування мікронерівностей поверхні за рахунок пластичного деформування частинками робочого середовища, які відтворюють в процесі роботи складні рухи [1-3].

Формування поверхневого шару в процесі вібраційної обробки відбувається під дією багаторазових мікроударів частинок робочого середовища, які викликають утворення слідів обробки, зміну геометричних і фізико-механічних параметрів поверхневого шару (шорсткості, мікротвердості, залишкових напружень і структури). Форма i розміри слідів обробки визначаються параметрами робочого середовища, режимами обробки, властивостями оброблюваного матеріалу.

Аналіз останніх досліджень і публікацій. Зацікавленість віброабразивними методами обробки деталей пояснюється рядом переваг цього методу при виготовленні деталей з високим класом чистоти поверхні. Це деталі підшипників кочення, інструмент (різці, свердла та фрези після термічної обробки і зварювання), деталі двигунів, верстатів, холодильників та ін. [2]. Важливою перевагою віброобробки є висока стабільність результатів обробки всіх деталей однієї партії, що особливо важливо при обробці високоточних деталей $[1,2]$.

До фінішних методів відноситься і вібраційна обробка деталей в різноманітних середовищах, яка забезпечує створення необхідної шорсткості i фізико-механічних властивостей поверхні та поверхневих шарів [3].

Вібраційна обробка деталей в абразивному середовищі відбувається з використанням певного обладнання. Віброустановка, як правило, містить джерело рушійної сили (вібратор) i контейнер для завантаження робочої суміші, яка включає оброблювані деталі, наповнювач 
(абразив), а також, при необхідності, рідинні розчини [4].

До технологічних факторів процесу відносяться: продуктивність при заданій якості, вибір абразивних матеріалів і режимів обробки, необхідність застосування хімічних добавок в робочі розчини або нагрівання їх з метою підвищення ефективності обробки [4].

Мета роботи. Розроблення комплексу експериментально-теоретичних підходів до дослідження закономірностей повільного циркуляційного руху робочого середовища у вібробункері та визначення впливу параметрів вібробункера на процес ударно-імпульсної обробки.

Викладення основного матеріалу. Розроблена нами вібраційна установка (рис. 1) містить робочу камеру, встановлену на з'єднаних 3 основою опорах, кінці кожної з яких споряджені пружинами, а днище робочої камери споряджене віброзбуджувачами, виконаними у формі електромагнітів. Кількість опор та електромагнітів дорівнює чотирьом. В залежності від послідовності включення електромагнітів формується необхідний циркуляційний рух робочого середовища [8].

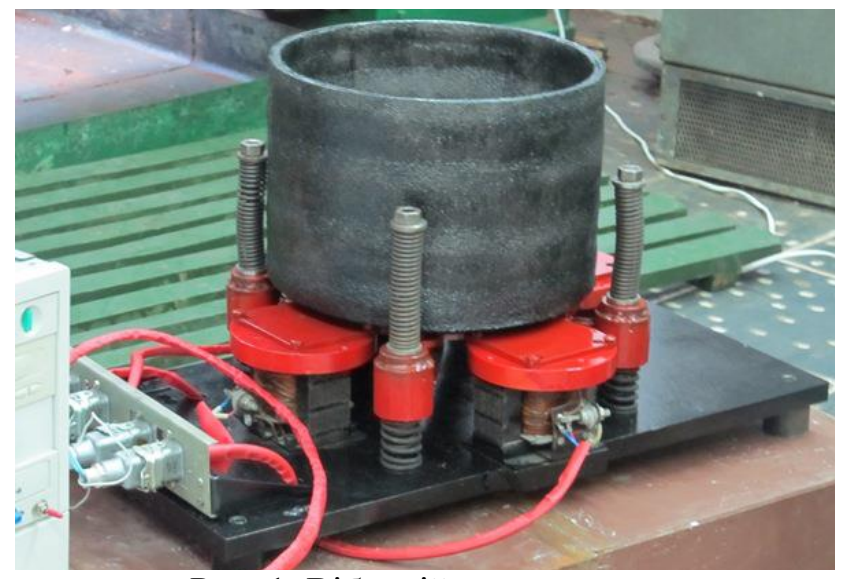

Рис. 1. Вібраційна установка

Закономірності руху розглянемо для різних випадків ударного навантаження. Ударні навантаження можуть здійснюватися за симетричною схемою, коли включені всі чотири електромагніти та за асиметричними схемами $[5,6,7]$.

При одночасному включенні всіх чотирьох електромагнітів вібробункер буде рухатись в напрямку осі $z$. В першому наближенні будемо вважати рух вібробукера синусоїдальним, відповідним синусоїдальній силі, що створюється електромагнітами. Ударне імпульсне навантаження на вібробункер відбувається при його взаємодії з упорами в точці 1 (рис. 2, a).

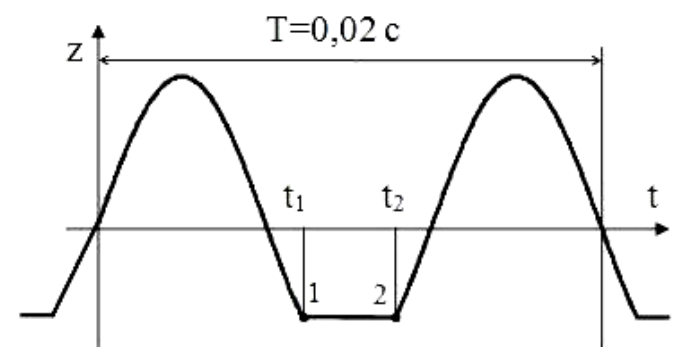

a)

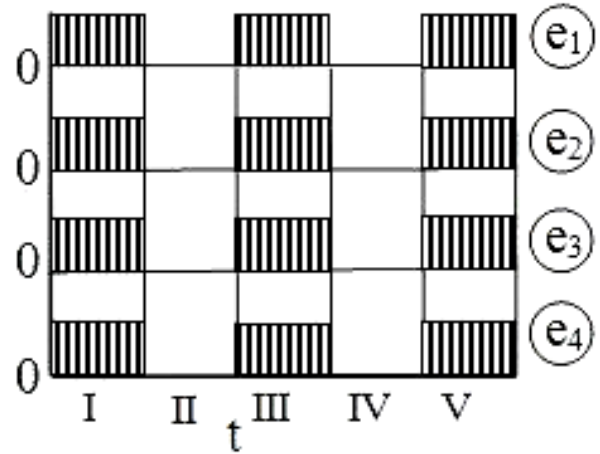

б)

Рис. 2. Закон переміщення корпуса вібробункера при його симетричному ударноімпульсному навантаженні (а) та циклограма одночасного включення всіх чотирьох електромагнітів (б)

Частота включення електромагнітів складає 50 Гц. Амплітуда переміщення 2 ... 3 мм. При ході вібробункера вниз він взаємодіє з упорами і зупиняється. При цьому, в робочому середовищі виникають інтенсивні процеси імпульсного характеру (рис. 2, б).

При ударі точки $\mathrm{D}_{1}, \mathrm{D}_{2}$ дна вібробункера взаємодіють 3 упорами і зупиняються (рис. 3 ). Робоче середовище і дно вібробункера рухаються по інерції. При цьому має місце пружна деформація дна вібробункера і він прогинається. Його точка $\mathrm{D}_{3}$ рухається вниз під дією сил

(C) Денисюк В.Ю., Симонюк В.П., Лапченко Ю.С., Кайдик О.Л., Пташенчук В.В. 
інерції дна та інерції середовища і зупиняється в стані динамічної рівноваги. При цьому гранули і деталі, які утворюють робоче середовище, зупиняються безпосередньо біля поверхні дна вібробункера. Еквівалентний тиск робочого середовища біля дна вібробункера підвищується на величину $p_{y 0}$. Елементи робочого середовища, розташовані вище дна, рухаються за інерцією (за стрілкою $V_{1}$ ), натискують на нерухомі елементи, розташовані біля дна, і гальмуються, підвищуючи тиск в області дна і розширює цю область. Утворюється ударна хвиля $\mathrm{F}_{1} \mathrm{~F}_{3} \mathrm{~F}_{2}$. Фронт ударної хвилі рухається вгору із швидкістю ударної хвилі $V_{a}$.

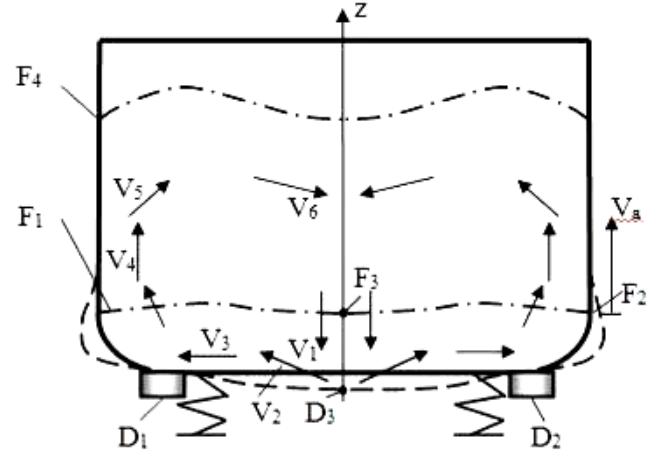

Рис. 3. Закон переміщення корпусу вібробункера при його симетричному ударно-імпульсному навантаженні

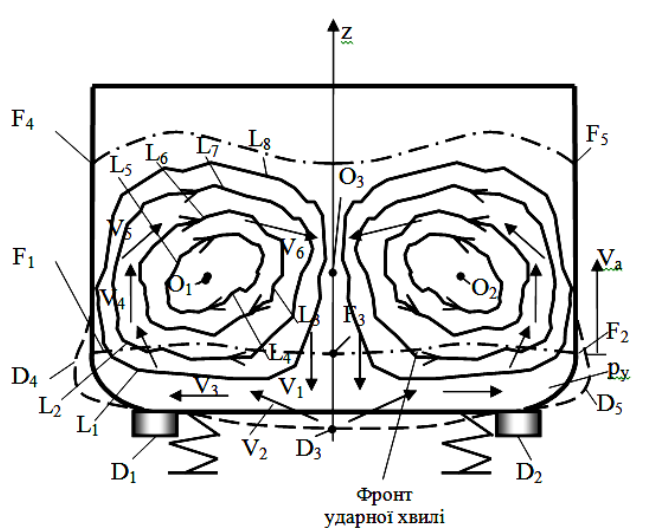

Рис. 4. Схема вісесиметричного вертикального переміщення вібробункера та циркуляційний рух робочого середовища

Третьою причиною є деформації стінок вібробункера в радіальному напрямку (точки $\mathrm{D}_{4} \mathrm{D}_{5}$ ) (рис. 4). Розширення вібробункера знижує еквівалентний тиск на периферії по відношенню до тиску в центрі. Це приводить до виникнення мікропереміщень елементів робочого середовища від центру до периферії. Переміщення показані стрілками $V_{2}$ i $V_{3}$. Фронт ударної хвилі $\mathrm{F}_{1} \mathrm{~F}_{2} \mathrm{~F}_{3}$ переміщується вгору по висоті вібробункера до тих пір, поки не досягне вільної поверхні робочого середовища. Вільна поверхня внаслідок проходження фронту дещо викривляється і набуває форми кривої $\mathrm{F}_{4} \mathrm{~F}_{5} \mathrm{~F}_{6}$ (викривлення показано у збільшеному вигляді).

Переміщення елементів робочого середовища спричиняє циркуляційний рух, який формується у радіальних площинах. Еквівалентні лінії течії (траєкторії руху елементів) $є$ замкнутими і являють собою кільцеві лінії, що мають нижні гілки $\mathrm{L}_{1}, \mathrm{~L}_{2}, \mathrm{~L}_{3}, \mathrm{~L}_{4}$ та верхні гілки $\mathrm{L}_{5}, \mathrm{~L}_{6}, \mathrm{~L}_{7}, \mathrm{~L}_{8}$. Циркуляційний рух $\epsilon$ повільним. Він охоплює весь об'єм робочого середовища. Циркуляційний рух має вигляд вихрового кільця з центром в точках $\mathrm{O}_{1}$ та $_{2}$.

Таким чином, при ударно-імпульсному навантаженні вібробункера в робочому середовищі виникає вихровий циркуляційний рух, який охоплює тороподібну область. В центрі тороподібної області (точки $\mathrm{O}_{1}$ та $\mathrm{O}_{2}$ ) має місце фокус течії, де їі поступальна швидкість близька до нуля.

Час розповсюдження фронту ударної хвилі від дна вібробункера до вільної поверхні $є$ фазою гідравлічного удару $\tau$.

$$
\tau=\frac{H}{v_{a}},
$$

де $H$ - висота робочого середовища; $v_{a}$ - швидкість ударної хвилі.

Швидкість розповсюдження гідроударної хвилі є невеликою і становить $50 \ldots 100 \mathrm{~m} / \mathrm{c}$. Сили опору в робочому середовищі $\epsilon$ надзвичайно інтенсивними. Тому гідроударне підвищення тиску швидко зменшується. Запропоновано як перше наближення, що підвищення тиску в околиці дна вібробункера змінюється за трикутним законом (крива 2 на рис. 5).

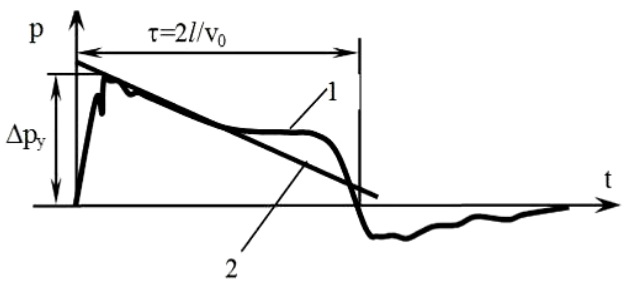

Рис. 5. Схематичний графік зміни гідроударного тиску у вібробункері при гідроударі 
Підвищення тиску спричинює циркуляційний рух робочого середовища, який направлений від середини дна вібробункера на його периферію (рис. 6). Робоче середовище розповсюджується повільним циркуляційним потоком, для частини потоку відповідної лінії $\mathrm{O}_{1} \mathrm{O}_{3} \mathrm{O}_{2}$ переміщення середовища відбувається під дією еквівалентного тиску.

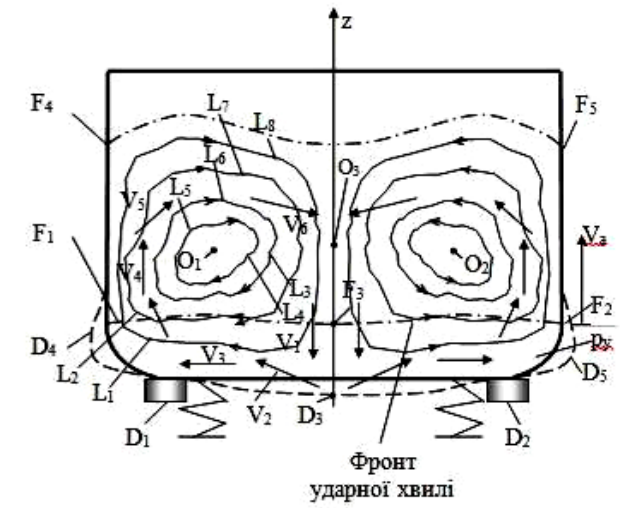

a)

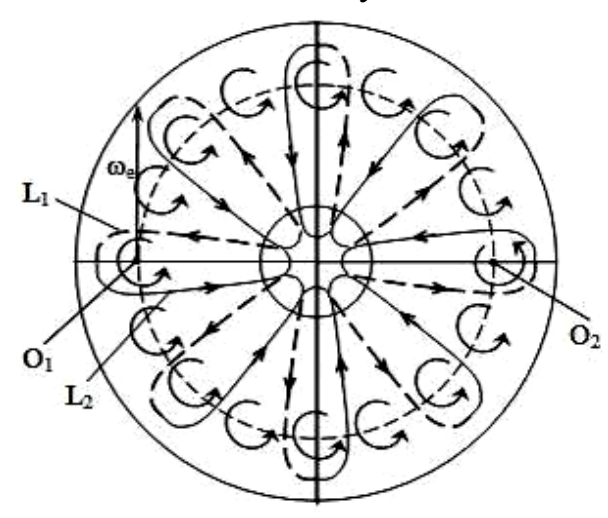

б)

Рис. 6. Циркуляційний рух робочого середовища при симетричному ударно-імпульсному навантаженні: (а) - вигляд збоку; (б) - вигляд згори

Прийнято, що еквівалентний тиск гідроудару становить $\frac{1}{2} p_{y}$. Даний тиск діє в проміжку часу $\Delta t_{B}=t_{2}-t_{1}$ між точками 1 і 2 (див. рис. 2 , а). При цьому, гідроудар діє в точці 1 і затухає в точці 2. Відповідно, еквівалентний тиск в околиці дна вібробункера складе:

$$
p_{Q 1}=\frac{1}{2} p_{y} \cdot \frac{\Delta t_{B}}{T} .
$$

Під дією еквівалентного тиску на лінії $\mathrm{O}_{1} \mathrm{O}_{3} \mathrm{O}_{2}$ має місце течія робочого середовища. Середня швидкість течії $V_{c}$ визначається за формулою:

$$
V_{c}=a_{1} \frac{\Delta t_{b}}{T}+a_{2} E_{\Pi}-a_{3} \rho+a_{4} V_{0}
$$

де $a_{1}-a_{4}-$ постійні, які будуть уточнені по результатам експериментів.

Вихровий циркуляційний рух приводить до повільного обертання маси робочого середовища. Профіль середніх швидкостей в радіальному перетині середовища описується параболічною залежністю. На осі вібробункера швидкість руху робочого середовища змінюється від нульового значення на поверхні та в центральній частині дна вібробункера до деякого максимального в центральній частині робочого середовища (точка $\mathrm{O}_{3}$ ). Таким чином виникає тороподібний вихровий циркуляційний рух робочого середовища (рис. 6,6$)$.

Інтенсивність циркуляційного руху оцінюється еквівалентною кутовою швидкістю $\omega_{e}$, що характеризує повільне обертання робочого середовища.

Для оцінки кутової швидкості циркуляційного руху використано залежність:

$$
\omega_{e}=\frac{V_{c}}{r_{c}} .
$$

Вихрові рухи охоплюють весь об'єм робочого середовища. Інтенсивність вихрового циркуляційного руху при симетричному ударному навантаженні $є$ невеликою. Це пояснюється стабілізуючим впливом окремих вихорів, які $\epsilon$ симетричними. Більш інтенсивним $\epsilon$ циркуляційний рух при несиметричному ударному навантаженні вібробункера (рис. 7).

При несиметричному навантаженні удар має місце з одного боку вібробункера (точка $\mathrm{D}_{1}$ ). При цьому ударна хвиля $\mathrm{F}_{1} \mathrm{~F}_{2} \in$ несиметричною. Підвищення тиску біля дна вібробункера приведе до його деформації. Деформація буде несиметричною, найбільший прогин дна буде зміщено до точки удару. Крім статичних деформацій дна і стінок вібробункера в ньому виникають високочастотні коливання. Це знижує сили тертя елементів робочого середовища по поверхні вібробункера. Дно вібробункера нахилено під деяким кутом до напрямку руху частинок абразиву. Тому інерція робочого середовища спричиняє його переміщення в напрямку стінки (показано стрілкою $V_{1}$ ). Це $\epsilon$ основною причиною формування інтенсивного циркуляційного руху робочого середовища. Додатковою причиною є проходження фронту

(с) Денисюк В.Ю., Симонюк В.П., Лапченко Ю.С., Кайдик О.Л., Пташенчук В.В. 
ударної хвилі.

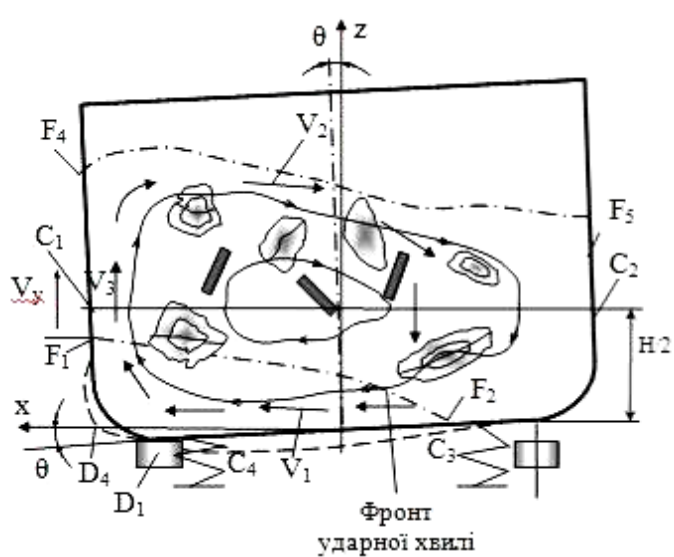

Рис. 7. Циркуляційний рух робочого середовища при несиметричному ударному навантаженні вібробункера

Експериментальні дослідження виконувалися для 3'ясування залежності показників інтенсивності та якості віброобробки від амплітуди коливань вібробункера. В якості дослідних зразків використовувались деталі типу тіл обертання, які мають зовнішню і внутрішню циліндричні, плоску і торцеву поверхні, що отримані різними способами (фрезеруванням, точінням) і мають різну початкову шорсткість. Це дало змогу з'ясувати ступінь оброблюваності кожного типу поверхні, оцінити ступінь заокруглення гострих кромок.

В результаті експерименту були отримані наступні значення розмаху коливань контейнера в залежності від завантаженості його робочою сумішшю (таблиця 1).

Таблиця 1

Результати експериментальних вимірювань розмаху коливань контейнера, мм

\begin{tabular}{|c|c|c|c|c|c|c|c|c|c|c|}
\hline \multirow{2}{*}{\multicolumn{2}{|c|}{$\begin{array}{c}\text { Рівень } \\
\text { завантаження } \\
\text { № } \\
\text { повторності }\end{array}$}} & \multicolumn{3}{|c|}{0 кг } & \multicolumn{3}{|c|}{1,5 кг } & \multicolumn{3}{|c|}{3 кг } \\
\hline & & 1 & 2 & 3 & 1 & 2 & 3 & 1 & 2 & 3 \\
\hline \multirow{4}{*}{ 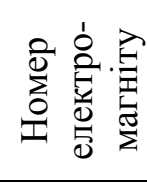 } & 1 & 2,0 & 1,5 & 2,0 & 1,5 & 1,5 & 1,5 & 1,0 & 1,0 & 1,0 \\
\hline & 2 & 2,5 & 1,5 & 2,0 & 1,5 & 1,5 & 2,0 & 1,0 & 1,5 & 1,0 \\
\hline & 3 & 2,5 & 2,5 & 2,0 & 1,5 & 1,0 & 1,0 & 1,0 & 1,0 & 1,0 \\
\hline & 4 & 2,5 & 2,5 & 2,5 & 2,0 & 1,5 & 2,0 & 2 & 1,5 & 1,5 \\
\hline \multicolumn{2}{|c|}{$\begin{array}{c}\text { Середнє } \\
\text { арифметичне }\end{array}$} & 2,4 & 2,0 & 2,1 & 1,6 & 1,4 & 1,6 & 1,2 & 1,2 & 1,1 \\
\hline \multicolumn{2}{|c|}{$\begin{array}{c}\text { Середнє } \\
\text { квадратичне }\end{array}$} & 2,4 & 2,0 & 2,1 & 1,6 & 1,4 & 1,7 & 1,3 & 1,3 & 1,1 \\
\hline
\end{tabular}

3 таблиці видно, що середнє арифметичне і середнє квадратичне значення розмаху коливань істотно не відрізняються, тобто можна зробити висновок про малі випадкові похибки вимірювань.

Експериментальні вимірювання здійснено безпосередньо у вібробункері. При вимірюванні застосований оптичний метод із покадровим реєструванням положення елементів робочого середовища. Здійснена покадрова зйомка поверхні робочого середовища у вібробункері. Частота кадрів становила 1 с. Обробка фото сусідніх кадрів послужила основою для встановлення координат набору окремих індивідуальних елементів робочого середовища.

Для кількох сусідніх кадрів визначимо координати окремої гранули абразиву або маркера. Встановимо послідовні положення окремих гранул на поверхні робочого середовища. Формується масив векторів положення окремих індивідуальних елементів у вигляді набору векторів, які визначають положення елемента робочого середовища на поверхні у вигляді точок $\mathrm{A} 1, \mathrm{~A} 2$, .. An; B1, B2, .. Br; C1, C2, .. Сq. Число точок вибирається достатньо великим для того, щоб описати рух на всій поверхні робочого середовища. Число векторів залежить від того, як довго знаходиться елемент на поверхні робочого середовища. Масив вибраних точок описує траєкторію частинок на всій поверхні робочого середовища. Траєкторія має вигляд ламаних ліній (рис. 8). 


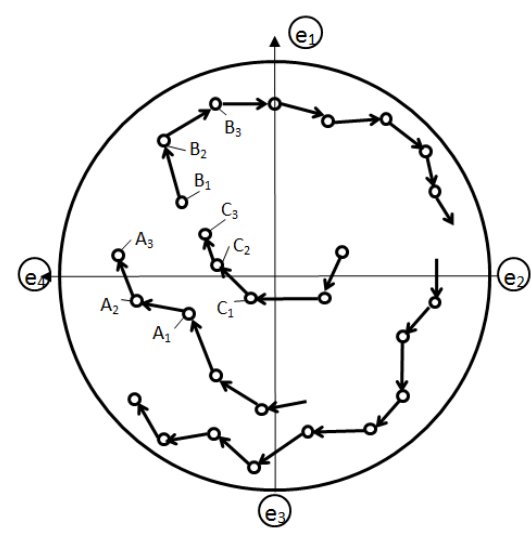

Рис. 8. Типові експериментально визначені траєкторії переміщення гранул на поверхні робочого середовища

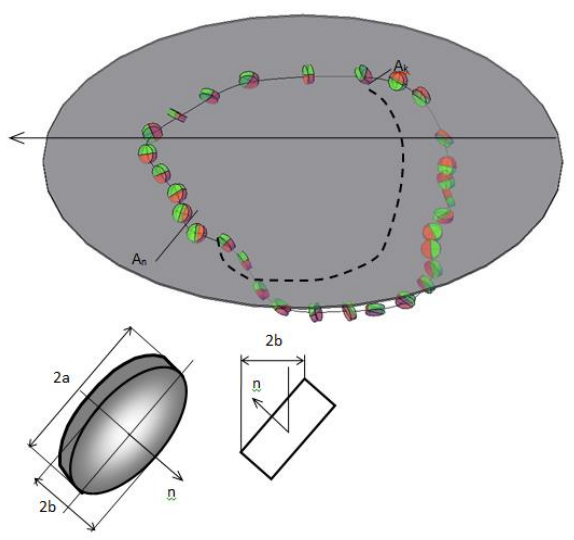

Рис. 9. Визначення поперечно-кутового положення маркера в робочому середовищі та прогноз траєкторії руху елемента в об'ємі робочого середовища

Для визначення швидкості повільного циркуляційного руху робочого середовища визначаються прирости координат елементів у сусідніх положеннях, які формуються у вигляді векторів [7]. формулою:

Лінійна швидкість переміщення елемента робочого середовища обчислюється за

$$
v_{A}=\frac{\varphi_{2}-\varphi_{1}}{\Delta t} \cdot R_{e}
$$

де $\varphi_{2}, \varphi_{1}$ - кутові координати елемента, визначені по сусіднім кадрам;

$\Delta t$ - інтервал часу між координатами;

$R_{e}$ - радіус колової траєкторії переміщення елемента робочого середовища.

Покадрова зйомка дає можливість визначити обертальні рухи деталей і гранул абразиву. Для цього застосовують маркери циліндричної форми невеликої величини (у вигляді диска). На окремих кадрах реєструється кутове положення деталі та використовується нормаль до ії контрольної поверхні (рис. 9).

Вектори нормалей по сусіднім кадрам $\vec{n}_{2}, \vec{n}_{3}, \vec{n}_{4}, \vec{n}_{5}$ визначаються за положенням диска. На фото диск реєструється у вигляді еліпса, різниця вісей якого визначає кути нахилу диска (рис. 9).

Кутове положення деталі визначається кутом $\theta$, який пов'язаний із співвідношенням вісей еліпса, відповідно значення:

$$
\theta=\arccos \left(\frac{b}{a}\right)
$$

Кутове положення диска в площині вісей координат хоу визначається кутом $\varphi$ між малою віссю еліпса та віссю $x$.

Із аналізу покадрової зйомки можна прогнозувати траєкторію руху деталей в об'ємі робочого середовища. Визначення прогнозної траєкторії руху імітується схемою (рис. 10).

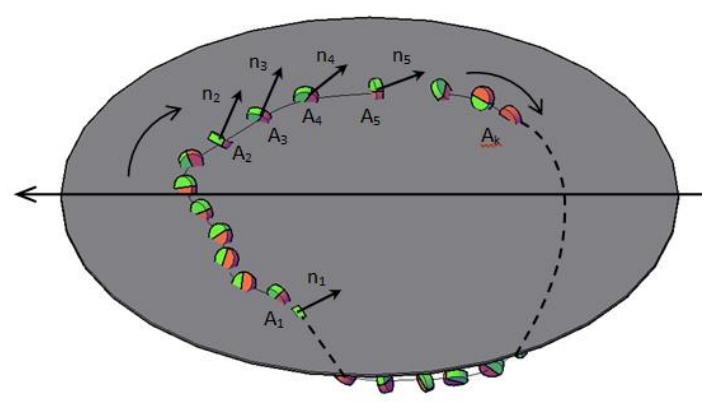

a)

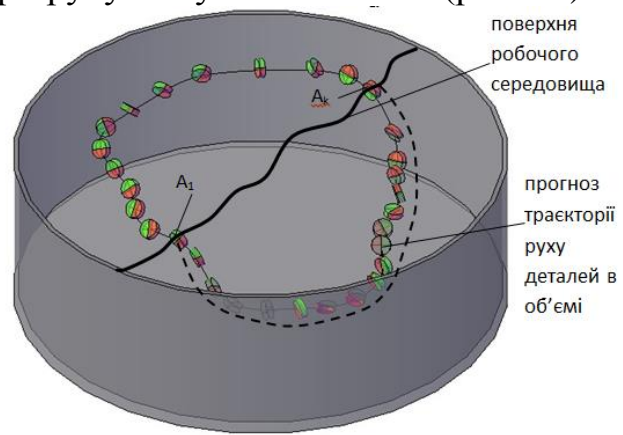

б)

Рис. 10. Визначення прогнозних значень траєкторії руху деталі в об'ємі робочого середовища

(a) - фіксований рух деталі на поверхні; (б) - просторовий рух деталей (прогноз траєкторії показано пунктирною лінією)

(C) Денисюк В.Ю., Симонюк В.П., Лапченко Ю.С., Кайдик О.Л., Пташенчук В.В. 
Для деталі (маркера) А здійснена покадрова зйомка. На кадрах фіксується положення деталі, починаючи з точки $\mathrm{A}_{1}$ і закінчуючи точкою $\mathrm{A}_{\kappa}$. В подальшому здійснювалась покадрова зйомка до тих пір, поки деталь знову не з'явилась на поверхні (близько точки $\mathrm{A}_{1}$ ). Траєкторія руху деталі показана пунктирною лінією. Вона може бути досить точно прогнозована. Точно визначається час знаходження деталі в об'ємі робочого середовища.

При вивченні процесу віброобробки за часом було встановлено, що зняття металу відбувається достатньо рівномірно протягом всього часу обробки 3 деяким збільшенням в початковий період, коли відбувається зняття відносно грубих мікронерівностей та закруглення гострих кромок [5].

Із збільшенням зернистості абразивного середовища, тобто розмірів гранул абразивної крихти, зняття металу зростає внаслідок збільшення маси зерен і збільшення глибини їх проникнення в метал, що викликає більш інтенсивну оброблюваність поверхні.

Висновки. Сферичний рух вібробункера визначається законом включення електромагнітів і приводить до спіралевидного руху вібробункера в усталених динамічних режимах. Перехідні процеси мають місце при включенні електромагнітів і проявляються у вигляді складних поперчено-кутових переміщеннях вібробункера. Перехідні процеси обумовлюють значні динамічні навантаження на робоче середовище.

В результаті досліджень встановлено, що ударно-імпульсні навантаження на вібробункер приводять до виникнення повільного циркуляційного руху робочого середовища. Даний рух інтенсифікується при несиметричному ударному навантаженні. Циркуляційний рух має вигляд кільцевого або дугоподібного вихрового кільця, яке охоплює весь об'єм робочого середовища. Для визначення характеру вихрового руху допустимим $\epsilon$ застосування закону зміни кількості руху в інтегральній формі для виділеного контрольного об'єму робочого середовища. Середня швидкість циркуляційного руху залежить від інтенсивності удару, швидкості вібробункера до удару та маси робочого середовища. Кутова швидкість вихрового руху пропорційна середній швидкості циркуляційного руху.

В робочому середовищі має місце хаотичний рух окремих елементів (гранул абразиву) який обумовлений ударними навантаженнями на гранулу з боку сусідніх гранул. Хаотичний рух проявляється у вигляді відхилень траєкторії руху окремої гранули від середньої траєкторії циркуляційного руху. Відхилення траєкторії близьке до гармонічного (синусоїдального) закону.

\section{Інформаційні джерела}

1. Бабичев А.П. Технологические испытания абразивных гранул из шлифовального шлама (на полимерном связующем) / А.П. Бабичев, Н.С Зинченко, О.К. Сикизова // Вопросы вибрационной технологии, 2006. - С 214-217.

2. Бабичев А.П. Физико-технологические основы методов обработки: учебное пособие для вузов / А.П. Бабичев. - Ростов-на-Дону: Феникс, 2006. -410 с.

3. Николаенко А.П. Исследование зависимости интенсивности вибрационной обработки от расположения вибровозбудителя / А.П. Николаенко, М.А. Калмыков // ВосточноЕвропейский журнал передовых технологий. - 2009. - № 2/5(38). - С. 54-57.

4. Струтинський В.Б. Вдосконалення обладнання та процесу ударно-імпульсної обробки деталей у вібробункері: монографія / В.Б. Струтинський, В.П. Симонюк, В.Ю. Денисюк Луцьк: СПД Гадяк Жанна Володимирівна друкарня "Волиньполіграф»" ${ }^{\mathrm{TM}}, 2016 .-139$ с.

5. Струтинський В.Б. Дослідження закономірностей повільного циркуляційного вихрового руху робочого середовища у вібробункері / В.Б. Струтинський, В.П. Симонюк, В.Ю. Денисюк / "Перспективні технології та прилади". Збірник статей. Випуск 10(1). м. Луцьк, червень 2017 р. - Луцьк: Луцький НТУ, 2017. - С. 176-185.

6. V. Symonyuk V. Denysiuk, Y. Lapchenko Experimental study of circulating vortex movement working environment in vibrobunker / Mechanics, Materials Science \& Engineering Journal. Volume 12, September 2017, Pages 41-54, DOI 10.2412/mmse.58.82.178 provided by.

7. Symoniuk V., Denysiuk V., Lapchenko Y. Processing of Parts Under Pulse Loading of a Vibrating Hopper // In: Ivanov V., Trojanowska J., Pavlenko I., Zajac J., Peraković D. (eds) Advances in Design, Simulation and Manufacturing III. DSMIE 2020. Lecture Notes in Mechanical Engineering. Springer, Cham. pp. 411-421 (2020). https://doi.org/10.1007/978-3-030-50794-7_40

8. Патент 126090 Україна, МПК В24В 31/06 (2006.01). Вібраційна установка / Симонюк В.П., Федорчук О.В., Денисюк В.Ю., Кайдик О.Л., Лапченко Ю.С./ Заявник і патентовласник: 
Луцький національний технічний університет, Луцьк; заявл. 04.12.2017; опубл. 11.06.2018; Бюл. №11. -4 с.

Денисюк В.Ю., к.т.н., Симонюк В.П., к.т.н., Лапченко Ю.С., к.т.н., Кайдик О.Л., к.m.н., Пташенчук В.В., к.m.н.

Луцкий национальный технический университет

\title{
ИССЛЕДОВАНИЕ ПРОЦЕССОВ ОБРАБОТКИ ДЕТАЛЕЙ ПРИ УДАРНО- ИМПУЛЬСНОЙ НАГРУЗКЕ ВИБРОБУНКЕРА
}

В статье представлены результаты исследований закономерностей ииркуляиионного вихревого движения рабочей среды и перемещения корпуса вибробункера при его симметрической ударно-импульсной нагрузке. Установлено, что ударно-импульсные нагрузки на вибробункер приводят к возникновению медленного ииркуляиионного движения рабочей среды, которое интенсифиџируется при несимметрической ударной нагрузке. Представлень результаты экспериментальных исследований процесса вибрационной обработки деталей, проверена воспроизводимость эксперимента и достоверность полученных результатов. Осуществлен анализ технологических возможностей виброобработки в широком диапазоне частоты и размаха колебаний. Наглядно представлены причины проблематичности выбора оптимальных режимов виброобработки и возможные направления их преодоления. Осуществлено моделирования различных режимов работы вибрационной установки. Анализ результатов позволил выявить принципы оптимального подбора режимов виброобработки. Установлено способ достижения режима работь вибрационной установки с максимально эффективным использованием механической энергии колебаний.

Ключевые слова: вибрационная абразивная обработка, вибробункер, изируляционный движение, электромагнит, абразивный материал, ударная волна.

\author{
V. Denysiuk, V. Symonyuk, Y. Lapchenko, O. Kaidyk, V.Ptachenchuk \\ Lutsk National Technical University
}

\section{RESEARCH OF PROCESSES OF PROCESSING OF PARTS DURING IMPULSE IMPULSE LOADING OF THE VIBROBUNKER}

The article presents the results of studies of the patterns of circulating vortex motion of the working medium and the movement of the body of the vibrating hopper under its symmetrical shockpulse load. It is established that shock-pulse loads on the vibrating hopper lead to a slow circulating motion of the working medium, which intensifies under asymmetric shock load. The results of experimental researches of the process of vibration processing of details are presented, the reproducibility of the experiment and the reliability of the obtained results are checked. The analysis of technological possibilities of vibration processing in a wide range of frequency and amplitude of oscillations is carried out. The reasons for the difficulty of choosing the optimal modes of vibration processing and possible ways to overcome them are clearly presented. Simulation of different modes of operation of the vibrating installation is carried out. The analysis of the results made it possible to identify the principles of optimal selection of vibration processing modes. The method of achieving the mode of operation of the vibrating installation with the most efficient use of mechanical vibration energy is established.

Keywords: vibration abrasive treatment, vibrating hopper, circulating motion, electromagnet, abrasive material, shock wave.

(C Денисюк В.Ю., Симонюк В.П., Лапченко Ю.С., Кайдик О.Л., Пташенчук В.В. 